\title{
Educational Management Systems and the Tutorial Class
}

\author{
Bill Davey and Arthur Tatnall \\ RMIT University and Victoria University, Australia \\ Bill.Davey@rmit.edu.au, Arthur.Tatnall@vu.edu.au
}

\begin{abstract}
Recent research by the authors has shown that University administrative systems are not designed with a view for use in the direct educational process. To attempt to discover the mechanisms for this failure in IT systems an indepth case study was conducted. The study involved an extremely well documented University administrative system, intended to support the tutorial classroom, called the Administrative Management System (AMS). Based on a well known PeopleSoft product the implementation and development of the system allowed a study of the dynamics within the educational institution. It was found that the vision of IT support for the classroom has not been achieved and that the process of developing a large system for the University involved steps that would, almost inevitably, lead to an emphasis on data gathering rather than relevant reporting.
\end{abstract}

Key words: Administrative management systems, university administration, university classrooms, teaching support.

\section{INTRODUCTION}

In studying the development of information systems it is quite common to find that a system has not fulfilled its potential because, although technically well designed, it failed to meet the needs of its users (Meredith and Mantel 1995). Even the best designed system that does not do what all its users want is of little overall value, and an important part of systems development is finding out the needs of all the users: "You must thoroughly understand the business needs before you can create a useful system" (Post 
1999). In an earlier ITEM paper (Davey and Tatnall 2003) we pointed out how the information systems literature stresses the necessity of involving users in the process of designing information systems (Fuller and William 1994; Lindgaard 1994; Lawrence, Shah and Golder 1997). If this is not done then these systems will not be as useful as they could be. Lawrence et al. (1997) point to a need to consult with all users while Lindgaard (1994) notes that a large body of research has shown that potential users do not make best use of information systems unless they feel that these systems have been designed with their involvement and in their interest. Tatnall (2001) points out that there is a body of research indicating that when centrally designed systems are seem as unresponsive to the needs of a group of users then these users will ignore this system and devise means of their own to achieve what they want. There is plenty of evidence that this happens frequently in many university departments (Davey and Tatnall 2003).

Recent research (Davey and Tatnall 2003) has shown that many university administrative systems are not designed with a view to being used in the direct educational process: to be of use in the tutorial classroom. Newton et al. (2003) point out that partly because of the way the data in university administrative systems is stored and accessed, absolutely no use can be made of these systems to improve teaching and learning. They note that a tension thus exists between the different purposes of management systems in both school and higher education, and that systems that are designed primarily with a view to the provision of management information are unlikely to be of use for classroom purposes. One Australian university set out with the intention of creating a system to provide support for academics, and this paper reports on a detailed study of its development and an investigation into the reasons for the large gap between the intentions of the system and the final outcome.

\section{THE GAP BETWEEN VISION AND REALITY}

A definition of academic management was set out by a high level university committee, producing a vision of what academic management might mean. Among the nine attributes of the system to be developed were: 


\section{Section 4 Defining characteristics of academic management}

\section{Successfully managing an educational services contract}

- Students receive personalised advice from course teams based on information and alerts from the AMS.

- Students monitor their own academic performance with up-to-date, accurate information on progress.

- Students are provided with formative feedback at key learning milestones (including assessments).

- $\quad$ Students receive early advice of academic progress.

- Course teams monitor students' progress and workload based on rules they set and are alerted to need for early intervention.

- $\quad$ AMS supports these processes, including triggering and recording formative feedback.

- AMS stores details of the learning agreement, any negotiated amendments, and facilitate automatic re-enrolment.

- Progress of employees is reported to enterprises as agreed.

- The AMS maintains links between individual learners and the employers' educational services contract.

\section{Supporting career-long relationship management}

- Expectations of a lifelong relationship with RMIT are introduced to all students before completion of their course.

- Faculties, departments/schools and course teams integrate and coordinate planning for alumni activities and networking.

- The AMS maintains records of all alumni and client enterprises.

- Staff work with students to provide career guidelines at graduation and career planning services on an ongoing basis.

- Staff continue to provide alumni with information about university learning opportunities at RMIT to support their career on an ongoing basis to encourage further engagements with RMIT.

7. Maximisation of well-being of RMIT's students, clients and staff

- AMS provides students and clients with comprehensive information on services, facilities and program or subject specific occupational health, well-being and safety issues and costs.

- Students are supported to identify special needs.

- $\quad$ RMIT responds to the plan and implement assistance as needed.

- $\quad$ AMS assists course teams identify and support diverse student needs.

Table 1: RMIT's vision of academic management

Interviews were conducted with senior and junior academics, administrative officers and several members of the development team. 
When shown the features above, all respondents reported that none of these features were actually extant in the Administrative Management System (AMS), nor was anyone aware of plans to include features that might support these ideals. Clearly there had been an implementation which ignored a large part of the originally envisaged functionality, and this was the functionality that an academic might be interested in when looking to improve the work done in academic classrooms.

In fact, the specifications of business processes included just these:

- Recruitment - automated information access supplemented by expert advice on programs, and university services including housing, finance, etc., and handling of individual queries.

- Selection and management of selection (based on established selection criteria and processes - with the ability for individual academic selection decisions remaining).

- Problem-solving and management of individual students. Enrolled students are allocated to a Student Case Manager who is their first point of contact for queries and problems.

- Customer Relationship Management - to facilitate and maintain RMIT's relationships with enterprise clients, including the supervision of the educational services contract.

- Timetabling.

- Program Team Management - including projects, quality assurance and monitoring cohort progress.

- Electronic courseware development and cataloguing.

- Provision of expert advice on AMS functionality, and ongoing training to Faculties Department and central service areas. 'Super Users'/Business Analysts of the AMS (Functional Analysts who have formed part of the implementation team and returned to their faculties/service areas with expert knowledge of the system).

- Research support.

Note that none of these points have to do with classroom activities. 
This is more starkly brought into focus when looking at the timelines for the project:

\begin{tabular}{|c|c|}
\hline $\begin{array}{r}\text { AMS Process } \\
\end{array}$ & Available: \\
\hline Updating of student details & Late Oct ' 01 \\
\hline Attendance Confirmation - updating and enquiry & Late Oct \\
\hline Grade Rosters & Late Oct \\
\hline Download of grade rosters in new format & Late Oct \\
\hline $\begin{array}{l}\text { Entry of results via Client Server, or upload of results (in either } \\
\text { previous HP format file or in the AMS download format file) }\end{array}$ & Late Oct \\
\hline Advisement reports etc. & Late Oct \\
\hline Negative Service Indicator maintenance \& enquiries & Late Oct \\
\hline Student Account Enquiries - by staff (Client Server) & Late Oct \\
\hline Student Account Enquiries - by student via web & Dec \\
\hline Reports and on-line enquiries & Late Oct \\
\hline Pilot of GradeBook for nominated courses & Early '02 \\
\hline Direct admissions for nominated programs & Late Oct \\
\hline VTAC admissions and offers & Late Oct \\
\hline $\begin{array}{l}\text { On-line International Applications (possible interim arrangement } \\
\text { initially) }\end{array}$ & Late Oct \\
\hline International Applications & Late Oct \\
\hline Re-enrolment by student via web on campus & Dec \\
\hline Re-enrolment by staff member via client server & Late Oct \\
\hline New enrolment by student via web on campus & Feb '02 \\
\hline New enrolment by staff member via client server & Late Oct \\
\hline
\end{tabular}

Table 2: Timeline for project implementation

Note that all of the processes envisaged are of straight data capture. It seems that the grand dream of an IT system supporting the whole education process had resulted in a routine student records storage system.

\section{FINDING REASONS FOR THE GAP}

The formal project team chart (above) shows how thinking on the AMS development became a reality. The diagram includes only officials recruited from the vendor or the administrative levels of the University. In theory any academic advice could be garnered from the faculty reference group.

The Minutes of the Academic Management System Reference Group of $2 / 2000$ show that of 41 members of the reference group, one Dean was 
represented by a department head but no other academic with teaching, or teacher supervision roles, was a member. By rollover time the reference group had grown to 62 members, none of whom were active teachers. At this meeting, it was announced that:

"The Functional Analysts are a key component of this Phase and will be consulting with various relevant experts across the University. A high level of automation is envisaged in order to streamline the procedures. Functional Analysts will be looking at the rules which the University already has in place, will be analysing whether these rules are consistent, informal or on an individual basis and will be working towards consistent procedures across the University system. The consistency of University procedures will lead to successful automation."

Again, the functional analysts were drawn exclusively from administrative support staff of the University. Research has shown (Martilla and McLean 1977) that it may be more effective for users to determine those factors they think important to the effective use of information systems. In a case study by Shah (2001) such a study of user input led to the identification of issues such as communication between the Information Systems Department and users, the speed of response of particular sections of the system and the existence of specific reports. A question arises as to the prevalence of features of a system that have importance to users, but have not been emphasised by the developers of the system. It seems that, in this case, the definition of user became one that excluded any officer directly related to teaching within the University.

\section{RETURN ON INVESTMENT}

We then looked for reasons for the sudden lurch from a vision of academic administrative support into the much more mundane world of student records capture, the first clue was found from documents explaining some advantages of the new system. The Return on Investment (ROI) indicated that a saving of 86 person years of effort per annum could be achieved within 5 years. This figure was based on a significant reduction in the number of paper transactions (currently 1.2 million documents per annum) associated with student administration.

The reduction in the amount of paperwork was to be achieved by:

- Business Process Re-engineering leading to the rationalisation and streamlining of academic procedures.

- Reduction in the number of appeals based on procedural errors.

- Increased self service for students including financial transactions, enrolment and class selection. 
- Reduced staffing required for enrolment and re-enrolment.

- Monitoring and enforcement of final result submission deadlines (approximately 20,000 results were incomplete at $1^{\text {st }}$ April 2000).

- Reduced errors in enrolment resulting in fewer enrolment variations. The major impacts on academic and teaching staff were considered to be:

- Direct input of assessment results thus obviating double handling and the need to check results input by admin staff.

- Immediate access to class lists without the need for intermediaries.

- Monitoring of timely completion of assessment.

- Automatic academic advisement with reduced call on academic staff to provide time to advise students on enrolment issues.

- Automated enrolment requiring much less academic staff time.

- Increased administrative assistance by redeployment of effort and re-skilling of administrative staff.

It can be seen that each of these justifications for the system was oriented around cost savings from automation. There was no discussion of intangible benefits, and benefits to classroom teaching at all.

\section{THE ROLE OF ADMINISTRATIVE SYSTEMS IN TEACHING SUPPORT}

As we noted in a previous discussion of aspects of this topic (Davey and Tatnall 2003), Fulmer and Frank (1997) point out that while these systems have been effective in business-related tasks such as inventory control, personnel management, cost analysis and audit, they have been "... far less effective at depicting the conditions of teaching and learning. ... They have not provided quality data for analysing and intervening in processes of teaching and learning." It should be noted that Fulmer and Frank were referring to administrative information systems in schools in these comments, but our research shows them to be equally true of many university systems.

In an earlier ITEM paper (Tatnall and Davey 1995) we also argued that educational management systems should make more use of the 'higher levels' of information system and provide decision support and executive information facilities rather than just transaction processing. These higher levels of support could provide a much better level of support for teaching. Newton et al. (2003) also suggest use of higher level functions such as decision support. Speaking mainly of school-based systems, they suggest that knowledge based systems may offer possibilities for tracking of student progress and diagnosis of learning problems. We would argue that such functions would also be of value in university systems. 


\section{A CUTTING-EDGE EXAMPLE}

An extract from the process description for the monitoring of student progress indicates the thinking at the time of the requirements definition:

"Each student who fails to meet academic requirements is sent a certified letter. All correspondence is certified to ensure that students obtain documentation from the University. A return receipt is returned to the relevant Faculty to ensure that documentation was received."

Clearly the developers here are seeing student progress monitoring as a system that requires monitoring of only the paperwork. There could have been mention of diagnosis from the data or supplying quality improvement data, but there was not. Since none of this was imagined, the process definitions excluded any real academic support.

Another clue as to what was envisaged by the system development team can be seen from the training schedules. This list of training courses shows that the system was seen as a means of recording data, rather than supplying information.

\begin{tabular}{|l|l|}
\hline AMS001 & AMS Basic, People \& Student Data \\
\hline AMS003 & Managing Organisations \\
\hline AMS004 & Communication, Comments \& Checklists \\
\hline AMS005 & Committees \& Events \\
\hline AMS007 & Managing Applications (Direct Local) \\
\hline AMS008 & International Applications \\
\hline AMS009 & Managing Evaluation and Matriculation - run as pilot only in 2001 \\
\hline AMS010 & Managing Student Records \& Enrolment \\
\hline AMS012 & $\begin{array}{l}\text { Class Scheduling - run as pilot only in 2001 - open for other staff mid- } \\
2002\end{array}$ \\
\hline AMS015 & Student Financial Basics \\
\hline AMS018 & Billing, Payment \& Refunds \\
\hline AMS019 & Administering Payment Plans \\
\hline
\end{tabular}

Table 3: Course numbers and names

\section{CONCLUSION}

This case study shows that administrative systems in university education are not immune to the vagaries of information systems designed for any other industry sector, and suffer the same problems if all stakeholders are not involved in their design. They are often not designed to take into account the 
possibilities of using their output to improve what goes on in the tutorial classroom. A 'grand plan' was envisaged by the University where a quick changeover to a robust data gathering and reporting system would quickly lead to improvements through web-based automation of interactions with clients (mostly students) so that the system would yield high-level academic returns. The reality that has been found by almost all sectors that take on a BPR (Business Process Re-engineering) exercise is that the data capture and reporting systems are non-trivial but still determine the possibility of leading on to higher-level use of the information. A further finding from the case study is that the inclusion of stakeholders at all times in the project seems necessary to maintain focus on the vision and avoid intricate, but often unhelpful, detail from becoming the only outcome. It is also noted that education organisations seem to be composed of two streams of management: teachers and administrators. These two streams seem, in the case study example at least, to have little idea of the priorities of the other.

\section{REFERENCES}

Davey, B. and Tatnall, A. (2003). Involving the Academic: A Test for Effective University ITEM Systems. Management of Education in the Information Age: The Role of ICT. Selwood, I., Fung A. C. W. and O'Mahony C. D. Assinippi Park, Massachusetts, Kluwer Academic Publishers / IFIP: 83-92.

Fuller, F. and William, M. (1994). Computers and Information Processing. Massachusetts, Boyd \& Fraser.

Fulmer, C. L. and Frank, F. P. (1997). Developing Information Systems for Schools of the Future. Information Technology in Educational Management for the Schools of the Future. Fung, A. C. W., Visscher A. J., Barta B. Z. and Teather D. C. B. London, Chapman \& Hall / IFIP: 122-130.

Lawrence, D. R., Shah, H. U. and Golder, P. A. (1997). Business Users and the Information Systems Development Process. The Place of Information Technology in Management and Business Education. Barta, B. Z., Tatnall A. and Juliff P. London, IFIP / Chapman \& Hall: 118-127.

Lindgaard, G. (1994). Usability Testing and System Evaluation. London, Chapman \& Hall.

Martilla, L. A. and McLean, E. R. (1977). "Importance Performance Analysis." Journal of Marketing(January).

Meredith, J. R. and Mantel, S. J. J. (1995). Project Management: a Managerial Approach. New York, John Wiley \& Sons Inc.

Newton, L. and Visscher, A. J. (2003). Management Systems in the Classroom. Management of Education in the Information Age: The Role of ICT. Selwood, I., Fung A. C. W. and O'Mahony C. D. Assinippi Park, Massachusetts, Kluwer Academic Publishers / IFIP: 189194.

Post, G. V. (1999). Database Management Systems. London, McGraw Hill.

Shah, S. K. (2001). "Improving Information Systems Performance Through Client Value Assessment: A Case Study." Review of Business 22(1/2): 37-42.

Tatnall, A. (2001). Design Strategies. Information Technology in Educational Management: Synthesis of Experience, Research and Future Perspectives on Computer-Assisted School 
Information Systems. Visscher, A. J., Wild P. and Fung A. C. W. Dordrecht, The Netherlands, Kluwer Academic Publishers: 97-113.

Tatnall, A. and Davey, B. (1995). Executive Information Systems in School Management: a Research Perspective. World Conference on Computers in Education VI. WCCE'95. Liberating the Learner. Tinsley, J. D. and van Weert T. J. London, IFIP / Chapman \& Hall: $579-588$. 